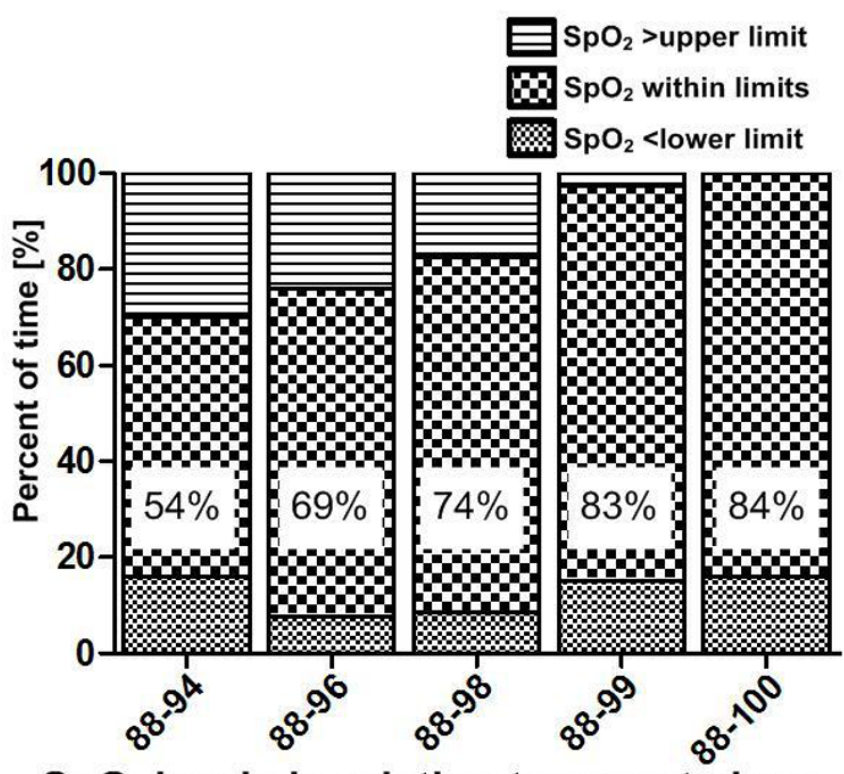

$\mathrm{SpO}_{2}$ levels in relation to preset alarm limits

[Figure 1]

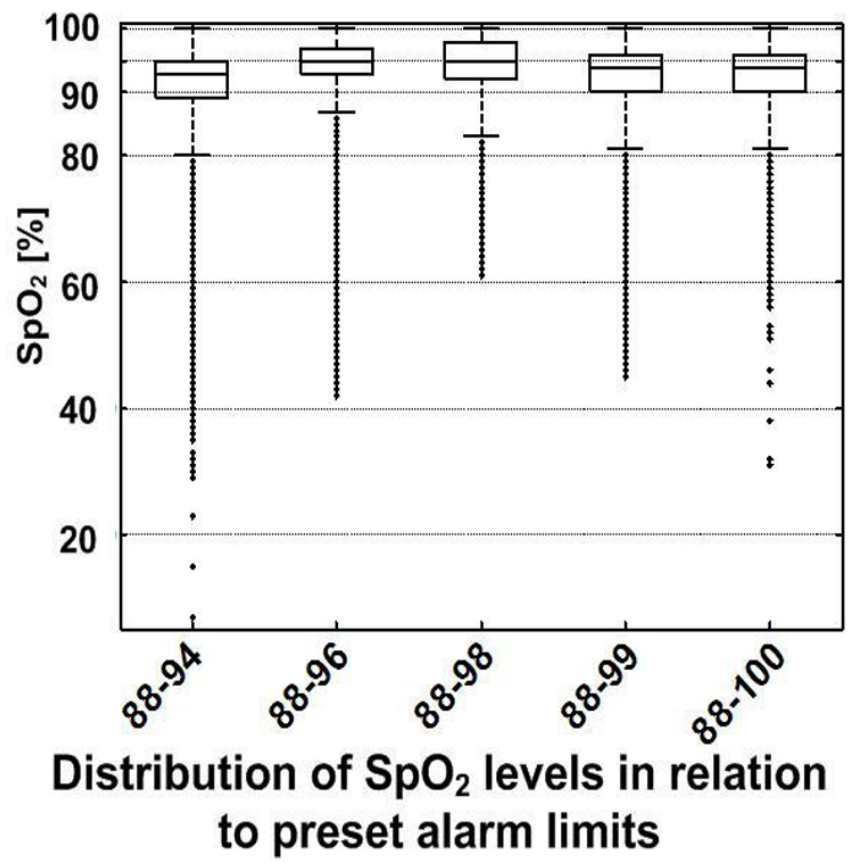

[Figure 2]
1329

\section{EARLY LUNG RECRUITMENT AT BIRTH IN A PRETERM LAMB MODEL: A PILOT STUDY}

\author{
D. Tingay ${ }^{1,2,3}$, R. Bhatia ${ }^{1,4}$, G. Schmolzer ${ }^{1,4}$
}

${ }^{1}$ Neonatology, Murdoch Childrens Research Institute, Parkville, ${ }^{2}$ Neonatology, Royal Children's Hospital, ${ }^{3}$ Paediatrics, University of Melbourne, ${ }^{4}$ Neonatal Research, Royal Women's Hospital, Melbourne, VIC, Australia

Background: The importance of achieving lung recruitment at birth is well recognised but the optimal strategy unclear.

Aim: To determine the feasibility of measuring regional lung mechanics during three lung recruitment strategies at birth, and their outcomes, in a preterm lung model.

Method: Nine 127d old lambs (mean weight $2.7 \mathrm{~kg}$ ) were studied. During delivery of head and thorax the fetus was intubated and electrical impedance tomography (EIT) electrodes applied . Once delivered one of three ventilation strategies was applied:

1. Sustained Inflation (SI+Surfactant): 20 sec $30 \mathrm{cmH}_{2} \mathrm{O}$ SI then PPV+Targeted Tidal Volume $(\mathrm{TTV} ; 7 \mathrm{~mL} / \mathrm{kg})$ at PEEP $6 \mathrm{cmH}_{2} \mathrm{O}$ and surfactant at 10-min.

2. Surfactant+SI: As per SI+Surfactant but surfactant pre-delivery.

3. Escalating PEEP: PEEP increased by $2 \mathrm{cmH}_{2} \mathrm{O}$ every 10-breaths from 4 to $20 \mathrm{cmH}_{2} \mathrm{O}$ during PPV+TTV, then decreased to PEEP at maximal $C_{\mathrm{rs}}$. Surfactant at $10-\mathrm{min}$.

In all strategies, $\mathrm{F}_{1 \mathrm{O} 2}$ and TTV were adjusted to maintain $\mathrm{Sp}_{\mathrm{O} 2} 88-92 \%$ and $\mathrm{Pa}_{\mathrm{CO} 2} 45-55 \mathrm{mmHg}$. Gas exchange, lung mechanics and regional lung volume/tidal volume (EIT) measured until 70-min life.

Results: There was no difference in regional EELV but at 8-min more uniform aeration occurred with escalating PEEP than Surfactant+SI; mean(SD) anterior:poster hemithorax aeration 0.6(0.4):0.7(1.2) vs 0.7(0.4):0.4(0.3) impedance units. Surfactant+SI and escalating PEEP improved oxygenation compared to SI+Surfactant (Fig). There were no sustained differences in $\mathrm{C}_{\mathrm{rs},} \mathrm{Pa}_{\mathrm{CO} 2}$ and $V_{\mathrm{T}}$. 
Conclusions: Exploring the interaction between type of recruitment manoeuvre and adjunctive therapies birth using methods which may be translatable to the clinical environment is feasible and may yield interesting results.

Figure 1. Influence of three different recruitment strategies at birth on $\mathrm{FIO} 2$ (A), $\mathrm{AaDO}_{2}$ (B), $\mathrm{PaCO}_{2}$ (C) and $\mathrm{V}_{T}$ (D)
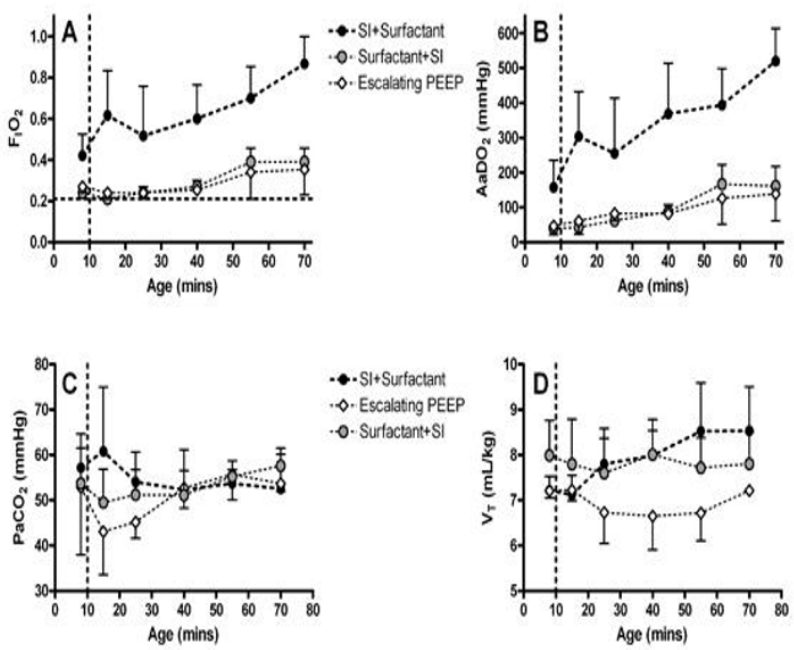

[Figure 1]

1330

CAN NON-INVASIVE VENTILATION BE AN ALTERNATIVE TO MANAGE RESPIRATORY FAILURE IN CHILDREN WITH MODERATE TO SEVERE NEUROLOGICAL IMPAIRMENT?

M. Cunningham ${ }^{1}$, D. Walter², S. Rajan¹, M. Vaidya ${ }^{1}$

${ }^{1}$ Paediatric Critical Care Unit, Barts and the London Children's Hospital, ${ }^{2}$ Medical Student, Imperial College School of Medicine, London, UK

Background \& aims: Invasive ventilation for respiratory failure in children

with moderate to severe neurological impairment is complex. We report the experience of non-invasive ventilation in these patients having moderate to severe neurological impairment in a 6 bedded paediatric critical care unit.

Methods: We retrospectively analysed a database of all children admitted unit at over a 33month period. We analysed the sub-group of children with moderate to severe neurological impairment who were ventilated, either invasively or non-invasively.
Results: Over the study period, of 362 (32.8\%) who required ventilatory support, 92 were classed as having moderate to severe neurological impairment. Demographic details are shown in Table.

Of the patients receiving both non-invasive and invasive ventilation, 6 failed with NIV, requiring invasive ventilation, while in 3 others received NIV post-extubation.

There was no significant difference between the groups in terms of length of stay $(p=0.112)$ or survival $(p=0.98)$.

Conclusions: NIV is a safe mode to support children with moderateto severe neurological deficit.

\begin{tabular}{|l|l|l|l|l|}
\hline & $\begin{array}{l}\text { NIV } \\
\text { exclusive }\end{array}$ & $\begin{array}{l}\text { IV } \\
\text { exclusive }\end{array}$ & $\begin{array}{l}\text { Mixed } \\
\text { IV/NIV }\end{array}$ & Total \\
\hline Total patients & 30 & 51 & 11 & 92 \\
\hline $\begin{array}{l}\text { "Age [yrs] } \\
\text { Median (IQR)" }\end{array}$ & $\begin{array}{l}5.40 \\
(1.73- \\
6.86)\end{array}$ & $\begin{array}{l}5.54 \\
(2.85- \\
10.42)\end{array}$ & $\begin{array}{l}4.93 \\
(3.44- \\
9.41)\end{array}$ & $\begin{array}{l}5.54 \\
(2.27- \\
9.49)\end{array}$ \\
\hline Sex M:F & $15: 15$ & $22: 29$ & $6: 5$ & $43: 49$ \\
\hline $\begin{array}{l}\text { "Days } \\
\text { ventilated } \\
\text { Median (IQR)" }\end{array}$ & $\begin{array}{l}1.5(0.25- \\
4.75)\end{array}$ & $1(1-2.5)$ & $6(1-8)$ & $1(1-4)$ \\
\hline $\begin{array}{l}\text { "Length of stay } \\
\text { Median (IQR)" }\end{array}$ & $2(1-6.75)$ & $\begin{array}{l}2(1- \\
11.08)\end{array}$ & $4(1-6)$ & $2(1-6)]$ \\
\hline Readmitted (\%) & $4(13.3)$ & $7(13.7)$ & $2(18.2)$ & $\begin{array}{l}13 \\
(14.1)\end{array}$ \\
\hline $\begin{array}{l}\text { "Survived (\% of } \\
\text { total patients)" }\end{array}$ & $28(93.3)$ & $50(98.0)$ & $10(90.9)$ & $\begin{array}{l}88 \\
(95.7)\end{array}$ \\
\hline $\begin{array}{l}\text { "PIM2 predicted } \\
\text { mortality (\%) } \\
\text { Median(IQR)" }\end{array}$ & $\begin{array}{l}1.08 \\
(0.70-\end{array}$ & $\begin{array}{l}3.20 \\
(1.28-\end{array}$ & $\begin{array}{l}1.15 \\
(0.98-\end{array}$ & $\begin{array}{l}1.59 \\
(1.1- \\
3.54)\end{array}$ \\
\hline
\end{tabular}

[Demographic Patient Profile]

\section{1}

\section{A COMPARISON OF DIFFERENT BEDSIDE TECHNIQUES OF DETERMINING ENDOTRACHEAL TUBE MALPOSITION}
G.M. Schmölzer ${ }^{1,2,3}$, R. Bhatia ${ }^{1,2}$, P.G. Davis ${ }^{1,2,4}$, D.G. Tingay ${ }^{1,2,5}$

${ }^{1}$ The Royal Women's Hospital, ${ }^{2}$ Murdoch Children

Research Institute, Melbourne, VIC, Australia, ${ }^{3}$ Medical University Graz, Graz, Austria, ${ }^{4}$ Obstetrics \& Gynaecology, The University of Melbourne, ${ }^{5}$ The Royal Children's Hospital, Melbourne, VIC, Australia

Background: Endotracheal tube (ETT) malposition is common but rapid identification of exact position of the tube is difficult at the bedside. 